\title{
Composition of cervical smears in patients with and without a cervical ectropion
}

\author{
F Buntinx, G G M Essed, H W H M Van der Putten, R F F Buchholz, J W Arends, \\ J A Knottnerus
}

\begin{abstract}
Aims-To test the hypothesis that absence of squamous cells in cervical smears obtained by an endocervical sampling technique is more prominent in patients with a cervical ectropion.

Methods-Prospective study exploring the relation between the composition of cervical smears obtained using an endocervical cotton swab in patients with $(n=188)$ and without $(n=341)$ a cervical ectropion. Subjects were 529 consecutive patients from whom a cervical smear was prepared at a university gynaecological clinic.

Results-In $7 \%$ of the endocervical samples no squamous cells were found. There was no correlation, however, between the presence or the size of an ectropion and the absence of squamous cells in those samples.

Conclusions-It was confirmed that endocervical sampling alone is insufficient to obtain good quality cervical smears. The presence of an ectropion proved to be an unreliable predictor of the absence of squamous cells.

(F Clin Pathol 1995;48:408-409)
\end{abstract}

Keywords: Cervical screening, quality assurance.

In a recent study ${ }^{1}$ we concluded that cervical sampling by an endocervical technique (Cytobrush) alone may result in false negative smears. This correlation was shown earlier by Spurret et $a l^{2}$ In our study a positive relationship between the absence of squamous cells in the Cytobrush sample and the probability of a false negative assessment was suggested as well.

A survey among general practitioners in Belgium $^{3}$ indicated that this topic was not merely of academic interest, as $16 \%$ of the respondents appeared to use the Cytobrush alone in the preparation of cervical smears.

In our previous paper, ${ }^{1}$ the hypothesis was put forward that the disadvantages of obtaining only a endocervical sample would be most prominent in patients with a cervical ectropion. This study aimed to test that hypothesis by comparing the absence of squamous cells in cervical smears prepared with an endocervical device alone in patients with and without cervical ectropion, using a combination of both endocervical swab and spatula as the diagnostic gold standard.

\section{Methods}

The study is based on 529 consecutive cervical smears prepared by three staff members of the gynaecological clinic of the University hospital of Maastricht, The Netherlands. For each patient a paired sample, using firstly a cotton swab and secondly an extended tip spatula, was produced. The age of the patient and the occurrence and degree of any cervical ectropion were registered during consultation. The presence of squamous and endocervical cells, respectively, was recorded for each sample by the university's cytology department.

The screening personnel in the cytology department were not aware of the aim of the study.

For each sampling method the relationship between the presence and the size of any ectropion and the presence of squamous and endocervical cells was examined. For statistical analysis the $\chi^{2}$ test and Fisher's exact test for independent proportions were used. The $\chi^{2}$ test for trend was used in analysing the relationship between the size of the cervical ectropion and the presence of the studied cell types. The $\mathrm{McNemar}$ test for paired samples was used to examine the significance of the relationship between the presence in the smear of both cell types and the sampling method employed.

A sample size computation was made before the start of the study, and updated whenever new data became available. Accepting a possible type I error of $5 \%$ and a type II error of $10 \%, 531$ smears would be sufficient to detect a difference of at least $10 \%$ in the number of samples lacking squamous cells between the groups with or without a cervical ectropion.

\section{Results}

There was a strong relationship between the sampling method (spatula or cotton swab) and the presence of both endocervical and squamous cells, the spatula performing better for both cell types $\left(\mathrm{p}<0.001 ; \chi^{2}\right)$.

\section{SQUAMOUS CELLS}

Squamous cells were lacking in 36/529 (7\%) of the cotton swab samples. In the presence of an ectropion these cells were absent in $4 \%$ of all cotton swab samples. Without an ectropion, they were absent in $8 \%$. The difference was not relevant or significant.

In spatula produced smears, only $8 / 529$ samples $(2 \%)$ lacked squamous cells. These samples were all derived from patients without cervical ectropion (table 1). 
Table 1 Presence of squamous cells in cervical smears from patients with and without cervical ectropion

\begin{tabular}{lccc}
\hline Squamous cells & Ectropion & No ectropion & Total \\
\hline \multicolumn{4}{c}{ Cotton swab sample } \\
Present & 180 & 313 & 493 \\
Absent & 8 & 28 & 36 \\
Total & 188 & 341 & 529 \\
\multicolumn{4}{c}{$\mathrm{p}=0.12\left(\chi^{2}\right)$} \\
Present & \multicolumn{2}{c}{ Spatula sample } \\
Absent & 188 & 333 & \\
Total & 0 & 8 & 521 \\
& 188 & 341 & 829 \\
& $\mathrm{p}=0.03$ (Fisher's exact) \\
\hline
\end{tabular}

We reconstructed table 1 by dividing the patients with cervical ectropion in two groups according to the size of the ectropion (either greater or smaller than one centimetre in diameter). We found neither a trend effect between the absence of squamous cells and the size of the ectropion $\left(p=0.08 ; \chi^{2}\right.$ for trend) nor a significant influence of an ectropion of more than one centimetre on the presence or absence of squamous cells in the smears (table 2).

\section{ENDOCERVICAL CELLS}

In spatula samples endocervical cells were absent in only $28 / 529$ cases $(5 \cdot 3 \%)$. In cotton swab samples, however, endocervical cells were absent in $219 / 529$ or $41 \%$ of the samples. In cotton swab samples, endocervical cells were absent more often in patients with $(94 / 188=$ $50 \%)$ than without $(125 / 341=37 \%)$ a cervical ectropion, $p=0.005\left(\chi^{2}\right)$. A significant linear relation was found between the absence of endocervical cells and the size of the ectropion $\left(\chi^{2}\right.$ for trend, $\mathrm{p}=0.003$ ).

\section{Discussion}

This study focuses on the relationship between cervical ectropion and the presence of squamous cells in cervical smears obtained by an endocervical sampling technique, using the combined smear as a gold standard. In this study the samples were taken by a cotton swab and $7 \%$ of those samples lacked squamous cells. It is uncertain that the results would have been similar if a Cytobrush had been used, which is not the custom in the outpatient de-

Table 2 Presence of squamous cells in cotton swab produced cervical smears by the size of a cervical ectropion (percentages in brackets)

\begin{tabular}{lllll}
\hline & & \multicolumn{3}{l}{ Cervical ectropion } \\
\cline { 3 - 5 } Squamous cells & $n(\%)$ & $\leq 1 \mathrm{~cm}$ & $>1 \mathrm{~cm}$ & Total \\
\hline Present & $313(92)$ & $72(96)$ & $108(96)$ & $493(93)$ \\
Absent & $28(8)$ & $3(4)$ & $5(4)$ & $736(7)$ \\
Total & $341(100)$ & $75(100)$ & $113(100)$ & $529(100)$ \\
\hline $\mathrm{p}=0.08\left(\chi^{2}\right.$ for trend); $\mathrm{p}=0.20\left(\chi^{2}\right)$.
\end{tabular}

partment of our University Hospital. However, since the same areas of the uterus are sampled by both methods, this seems rather likely. Kawaguchi et $a l^{4}$ compared the rates of cervical smears lacking squamous cells in Cytobrush and cotton swab samples and did not find any significant difference.

A study of published reports ${ }^{4-6}$ showed that rates of Cytobrush-obtained samples lacking squamous cells varied from $0 \cdot 4 \%$ to $23 \cdot 6 \%$. Only one paper reports on the cotton swab technique used alone. ${ }^{4}$ In this study, $1 \%$ of cervical smears lacked squamous cells.

The high proportion of smears lacking endocervical cells when obtained by endocervical sampling alone is in agreement with published reports. ${ }^{7}$ Our finding that the absence of endocervical cells in endocervical samples is more frequent when ectopia cervicis is present was confirmed by the detection of a linear relationship between the probability of a smear without endocervical cells and the size of the ectropion.

In this study, designed to reach a power of $90 \%$, we were not able to show a relationship between the presence or size of a cervical ectropion and the absence of squamous cells in cotton swab samples. The explanation for these observations $^{12}$ is, however, not clear. One possible reason for the lack of such a relationship could be that the epithelium of the ectropion may undergo squamous metaplasia, while still showing an ectropion on clinical examination, as described by Boon and Suurmeyer. ${ }^{8}$

These observations, however, confirm our view that endocervical sampling alone, whether carried out by brush or cotton swab, is insufficient to obtain good quality cervical smears. ${ }^{1}$ Moreover, the presence or absence of a cervical ectropion cannot be considered a predictor of the absence of squamous cells in endocervical smears.

This study was made possible by the help of the staff of the gynaecologic clinic and the cytology department of the University Hospital Maastricht.

1 Buntinx F, Boon ME, Beck S, Knottnerus JA, Essed GGM. Comparison of Cytobrush sampling, spatula sampling and combined Cytobrush-spatula sampling of the uterine cervix. Acta Cytol 1991;35:64-8.

2 Spurrett B, Ayer B, Pacey NF. The inadequacies of instruments used for cervical screening. Aust NZ $\mathcal{f}$ Gynaecol 1989;29:44-6.

3 Buntinx F, Crebolder H, Knottnerus A. Cervixuitstrijkjes: Afnamegewoonten en ervaringen. Huisarts $N u$ 1991;20: 13-6.

4 Kawaguchi K, Nogi M, Ohya M, Nishikawa Y, Kobayashi TK. The value of the Cytobrush for obtaining cells from TK. The value of the Cytobrush for obtaining cells

5 Doomewaard H, van der Graaf Y. Contribution of the Cytobrush to determining cellular composition of cervical smears. f Clin Pathol 1990;43:393-6.

6 Willcox F, Van Roy J. Gebruik van Cytobrush bij de afname van cervixuitstrijkjes. Tijdschr Belg Ver Labor 1989;16:47-8. 7 Buntinx F, Essed GGM, Knottnerus JA, Crebolder HFJM. The effect of different sampling devices on the presence of endocervical cells in cervical smears. A meta-analysis. Eur 7 Cancer Prev 1994;3:23-30.

8 Boon ME, Suurmeijer AJH. The Pap smear. Leiden: Coulomb Press, 1991. 